\title{
ENSAIO DE PENETRABILIDADE DE ÍONS CLORETOS NO CONCRETO: INFLUÊNCIA DA INCORPORAÇÃO DE ESCÓRIA DE ACIARIA BSSF
}

\author{
DIAS, ALISSON RODRIGUES DE OLIVEIRA \\ Mestre em Engenharia Civil \\ Universidade Federal do Ceará - UFC \\ Ceará; Brasil \\ rodrigues_alisson@live.com
}

\author{
LUCAS, SARAH OLIVEIRA \\ Graduanda em Engenharia Civil \\ Universidade Federal do Ceará - UFC \\ Ceará; Brasil \\ saraholiveiraluks@gmail.com
}

\author{
AMANCIO, FELIPE ALVES \\ Mestre em Engenharia Civil \\ Universidade Federal do Ceará - UFC \\ Ceará; Brasil \\ felipeaamancio@hotmail.com
}

\author{
CABRAL, ANTÔNIO EDUARDO BEZERRA \\ Professor Doutor em Engenharia Civil \\ Universidade Federal do Ceará - UFC \\ Ceará; Brasil \\ eduardo.cabral@ufc.br
}

\section{RESUMO}

As manifestações patológicas em estruturas de concreto podem ocorrer de diferenciadas formas, para o concreto armado, tem-se a corrosão das armaduras como uma das manifestações mais recorrentes. Relação água/cimento, grau de hidratação, porosidade, ambiente marinho, umidade relativa do ar, temperatura e ação do vento são alguns dos principais fatores que desencadeiam o processo de corrosão das armaduras do concreto armado. Assim, objetivou-se verificar a capacidade dos concretos produzidos com a incorporação de escória de aciaria BSSF em inibir a penetração de íons cloreto, por meio do ensaio de penetrabilidade de íons cloretos, avaliando-se a carga total passante, conduzido segundo a norma ASTM C 1202:2012 - Standard Test Method for Electrical Indication of Concrete's Ability to Resist Chloride Ion Penetration. Para tanto, foram produzidos cinco traços de concreto de classe de resistência de $40 \mathrm{MPa}$, com a substituição do agregado miúdo natural por escória de aciaria BSSF, em volume, nos teores de 0\%, 25\%, 50\% 75\% e 100\%. Além do ensaio de penetrabilidade de íons cloretos, realizou-se a caracterização dos concretos estudados por meio dos ensaios de resistência à compressão axial, absorção de água e índice de vazios. Os resultados obtidos demonstraram que o traço de referência (teor de $0 \%$ ) apresentou uma classe de penetrabilidade baixa, ao passo que todos os traços produzidos com a incorporação de escória de aciaria BSSF apresentaram classe de penetrabilidade moderada, segundo a classificação da ASTM C1202:2012. Apesar de ser mantida a mesma classe nesses traços alternativos, foi possível observar um aumento dos valores de carga passante à medida que ocorreu o aumento do teor de substituição. Este efeito é ocasionado, principalmente, pelo aumento da porosidade e permeabilidade dos concretos produzidos com escória de aciaria BSSF.

Palavras-chave: concreto, penetração de íons cloreto, escória de aciaria BSSF, ASTM C1202.

\section{ABSTRACT}

Pathological manifestations in concrete structures can occur in different ways. For reinforced concrete, steel corrosion is one of the most recurrent manifestations. Water/cement ratio, degree of hydration, porosity, marine environment, relative humidity, temperature and wind action are some of the main factors that trigger the corrosion process of reinforced concrete. Thus, the objective was to verify the ability of the concretes produced with the incorporation of BSSF steel slag to inhibit the penetration of chloride ions through the penetration test of chloride ions, by evaluating the total passing charge conducted according to ASTM standard C1202:2012 - Standard Test Method for Electrical Indication of Concrete's Ability to Resist Chloride Ion Penetration. For this purpose, five mixes of $40 \mathrm{MPa}$ strength class concrete were produced, replacing the natural fine aggregate for BSSF steel slag, by volume, in the contents of 0\%, 25\%, 50\% 75\% and $100 \%$. In addition to the penetrability test of chloride ions, the characterization of the studied concretes was performed through the tests of axial compressive strength, water absorption and voids index. The results showed that the reference mix $(0 \%$ content) presented a low penetrability class, while all traces produced with the incorporation of BSSF steel slag presented moderate penetrability class, according to ASTM C1202:2012 classification Although the same class was maintained in these alternative mixes, it was possible to observe an increase of the charge passed values as the substitution content increased. This effect is mainly caused by the increase of porosity and permeability of concretes produced with BSSF steel slag.

Keywords: concrete, chloride ions penetration, BSSF steel slag, ASTM C1202. 


\section{INTRODUÇÃO}

O concreto é um dos materiais mais utilizado mundiamente, ficando atrás somente da água (MEHTA; MONTEIRO, 2013). Sendo o concreto armado a opção estrutural de maior uso dentro da construção civil, por suas qualidades de resistência mecânica, flexibilidade e custos. Seu uso iniciou por volta de 1850, tempo no qual acreditava-se que a vida útil do concreto armado era ilimitada. Entretanto, com o passar do tempo, diversas manifestações patológicas foram surgindo, afetando as estruturas de concreto, como fissuras, eflorescências, corrosão de armaduras, entre outras.

Para o caso de corrosão das armaduras, uma das piores situações que pode ser encontrada é o caso de ataque por íons cloreto. A camada de cobrimento de concreto, quando de boa qualidade e espessura satisfatória, pode proteger a armadura contra a ação dos cloretos. Entretanto, conforme afirma Medeiros et al. (2013), sendo o concreto um meio poroso e suscetível a fissuras superficiais, a camada de cobrimento pode não satisfazer as condições de barreira contra a entrada de íons cloreto. A entrada de tais íons na estrutura pode acarretar a corrosão das armaduras de forma pontual e bastante agressiva, pois os íons não são consumidos no processo e seguem despassivando a camada protetora das barras da armadura, sendo um considerado um processo de rápida evolução, superior à da corrosão ocorrida por causa de carbonatação (BASHEER et al., 2001).

Em geral, esta corrosão é causada pelo ataque destrutivo dos íons cloreto que penetram por difusão e/ou outros mecanismos de penetração a partir do exterior (RINCÓN, 2006). Tal ataque acaba por ocasionar à redução da resistência, facilidade de manutenção e estética da estrutura (SHI et al., 2012). Os cloretos são prejudiciais ao concreto armado, pois com a chegada destes íons à armadura de aço, ocorre uma fragmentação do concreto, o que acaba por gerar a entrada de novos íons cloretos aos níveis subsequentes da armadura (AÏTCIN, 2003).

A partir disso, a durabilidade do concreto passou a ser considerada como um assunto importante, para os engenheiros e para toda a sociedade (MEDEIROS et al., 2013). Durabilidade é, segundo Silva Filho (1994), "a capacidade de um produto satisfazer, durante um período de tempo previsto em concepção, as exigências a ele impostas, sejam estas de origem técnica ou subjetiva, quando exposto a um ambiente previamente determinado". Por vida útil de um material entende-se o período de tempo durante o qual as suas propriedades permanecem acima dos limites mínimos especificados sem que haja a necessidade de intervenção ou reparos (SOUZA; RIPPER, 1998). A NBR 6118 (ABNT, 2014) define vida útil de uma maneira mais ampla, ou seja, como um período de tempo durante o qual a estrutura mantém as características originais, desde que sejam atendidos os requisitos de uso e manutenção prescritos pelo projetista e pelo construtor, bem como de execução dos reparos necessários decorrentes de eventuais danos acidentais.

Atrelado a essa busca por maior durabilidade desse material, também há uma procura de materiais alternativos que venham a substituir total ou parcialmente algum dos seus componentes, visando também melhorar suas características mecânicas e obter resultados econômicos satisfatórios.

Concernente a isso, atualmente há estudos voltados à análise da viabilidade da escória de aciaria incorporada ao concreto. Essa escória é um resíduo industrial com alto teor de materiais pesados pois é o subproduto fundido de muitas operações metalúrgicas, que após arrefecidas, são estocadas no pátio das siderúrgicas, para posterior uso, ou, infelizmente, em muitos casos, ser eliminada (GARCIA-GUINEA et al., 2010). O descarte desses resíduos e coprodutos apresentam inúmeros inconvenientes, tais como: necessidade de grandes áreas; elevado custo de transporte e preparação da área de descarte; perda de materiais; e degradação do meio-ambiente (SILVIA, et al., 2006; SZEKELY, TRAPAGA, 1995).

Devido a possibilidade de ocorrência de expansões, causadas principalmente, pelo alto teor de óxido de cálcio $(\mathrm{CaO})$ e óxido de magnésio (MgO) livres (HUANG et al., 2010; CHEN, 2011; BRAND; ROESLER, 2015), a escória de aciaria ainda é pouco aplicada em materiais cimentícios. Quando hidratados, ocorre o aumento de volume, ou seja, a expansão do material. A cal livre é responsável pela expansão a curto prazo, quando é transformada, em presença de umidade, em cal extinta. Já o óxido de magnésio é responsável pela expansão a longo prazo, devido suas reações serem mais lentas; também não são todos os casos de óxidos de magnésio que são prejudiciais, apenas os que se encontram de forma livre, sem estarem combinados (MO et al., 2017). Para o atual aproveitamento da escória de aciaria é necessário um período de envelhecimento que dura em torno de dois a dezoito meses de estocagem. Em certas regiões, esse período pode se tornar prejudicial para a competitividade da escória de aciaria em comparação aos materiais tradicionais (CHESNER et al., 2001). Por isso, a incorporação desse resíduo na produção de concretos ainda é pouco explorada no Brasil. Nesse sentido, a Baosteel, uma empresa siderúrgica chinesa, desenvolveu um novo tratamento para as escórias de aciaria, onde a escória fluida é basculada em um tambor rotativo, sendo resfriada rapidamente com jatos de água (LIU; WANG, 
2011), visando minimizar o efeito das reações expansivas de seus componentes e viabilizar a sua aplicação em outros setores. Como resultado desse processo tem-se a obtenção da escória de aciaria do tipo Baosteel Slag Short Flow BSSF, um material granulado, de fase vítrea, livre dos efeitos de expansão e que pode ser utilizado de imediato, sem a necessidade de tempo de envelhecimento (LI; GUO, 2014; LIU; WANG, 2011). No Ocidente, a Companhia Siderúrgica do Pecém - CSP é a única empresa siderúrgica que incluiu esse processo na sua linha de produção do aço até o presente momento.

Diante do exposto, torna-se necessário investigar a durabilidade do concreto quando nele é incorporada a escória de aciaria BSSF, investigando como a mesma influencia na sua durabilidade. Assim, o presente trabalho irá avaliar qual a resistência a penetração acelerada de íons de cloreto em concretos incorpordados com escória de aciaria BSSF.

\section{MATERIAIS E MÉTODO DE PESQUISA}

\subsection{Materiais}

Para a realização dessa pesquisa foi utilizado cimento Portland CP V - ARI, o qual apresenta pequena quantidade de adições, diminuindo as interferências que pudessem vir a ocorrer por conta da presença de adições minerais. A água utilizada foi da própria Região de Fortaleza e atendeu aos requisitos da ABNT NBR 15900-1 (ABNT, 2009). O aditivo foi do tipo superplastificante da linha MasterGlenium ACE 402, composto por carboxilatos. O aditivo possui possui pH de 7 , densidade de $1,15 \mathrm{~g} / \mathrm{cm}^{3}$ e solubilidade em agua de $100 \mathrm{~g} / \mathrm{L}$.

Os agregados miúdos e graúdos utilizados foram provenientes da Região Metropolitana de Fortaleza, atendendo à NBR 7211 (ABNT, 2009). As britas 12,5 mm e $19 \mathrm{~mm}$ eram de origem granítica e foram utilizadas como agregado graúdo. Como agregado miúdo foi utilizado areia grossa, extraída de rio, lavada e peneirada e escória de aciaria BSSF produzida na Companhia Siderúrgica do Pecém - CSP (Figura 1).

a)

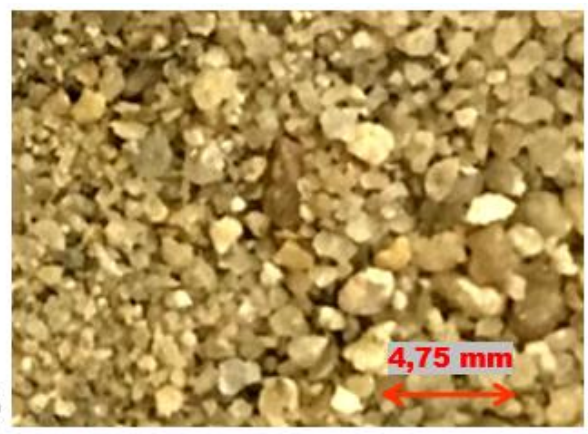

b)

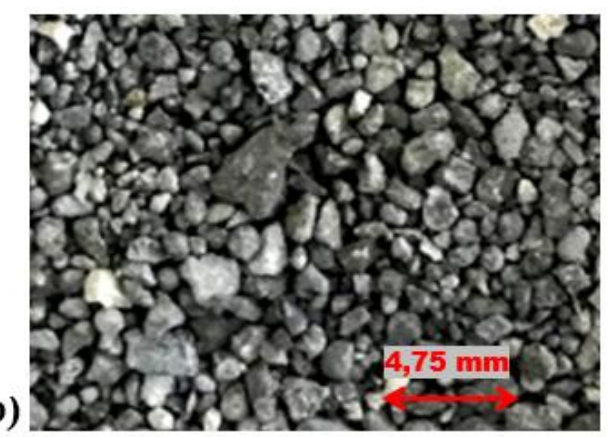

Figura 1: Imagem ampliada de partículas dos agregados miúdos utilizados na pesquisa: a) agregado miúdo natural, b) escória de aciaria BSSF.

A Tabela 1 apresenta as propriedades físicas dos agregados utilizados. Os ensaios foram realizados no Laboratótio de Materiais de Construção Civil - LMCC da Universidade Federal do Ceará - UFC. A granulometria dos agregados miudos é apresentada na Figura 2. A curva granulométrica enquadra-se na zona utilizável. Destaca-se que foi realizado o ajuste granulométrico da escória de aciaria BSSF com o da areia natural, no intuito de evitar variáveis no estudo, ao passo que a distribuição granulométrica dos agregados influencia nas propriedades do estado fresco e endurecido do concreto. 
Tabela 1 - Características físicas dos agregados miúdos e graúdos utilizados na pesquisa.

\begin{tabular}{|c|c|c|c|c|c|}
\hline Ensaio & Norma técnica & $\begin{array}{c}\text { Areia } \\
\text { natural }\end{array}$ & $\begin{array}{c}\text { Escória } \\
\text { BSSF }\end{array}$ & $\begin{array}{c}\text { Brita } \\
12,5 \mathrm{~mm}\end{array}$ & $\begin{array}{l}\text { Brita } \\
19 \mathrm{~mm} \\
\end{array}$ \\
\hline $\begin{array}{l}\text { Diâmetro máximo } \\
\text { característico }(\mathrm{mm})\end{array}$ & $\begin{array}{c}\text { ABNT NBR NM } \\
248: 2003\end{array}$ & $4,75 \mathrm{~mm}$ & $4,75 \mathrm{~mm}$ & $12,5 \mathrm{~mm}$ & $19 \mathrm{~mm}$ \\
\hline Módulo de finura (adim) & $\begin{array}{c}\text { ABNT NBR NM } \\
248: 2003\end{array}$ & 2,65 & 2,65 & 5,99 & 6,84 \\
\hline Massa unitária $\left(\mathrm{g} / \mathrm{cm}^{3}\right)$ & $\begin{array}{c}\text { ABNT NBR NM } \\
45: 2006\end{array}$ & $1,41 \mathrm{~g} / \mathrm{cm}^{3}$ & $2,08 \mathrm{~g} / \mathrm{cm}^{3}$ & $1,41 \mathrm{~g} / \mathrm{cm}^{3}$ & $1,37 \mathrm{~g} / \mathrm{cm}^{3}$ \\
\hline Absorção de água (\%) & $\begin{array}{c}\text { ABNT NBR NM } \\
30: 2001\end{array}$ & $0,9 \%$ & $2,1 \%$ & $0,89 \%$ & $0,94 \%$ \\
\hline Massa específica $\left(\mathrm{g} / \mathrm{cm}^{3}\right)$ & $\begin{array}{c}\text { ABNT NBR NM } \\
\text { 52:2009 }\end{array}$ & $2,59 \mathrm{~g} / \mathrm{cm}^{3}$ & $3,62 \mathrm{~g} / \mathrm{cm}^{3}$ & $2,61 \mathrm{~g} / \mathrm{cm}^{3}$ & $2,61 \mathrm{~g} / \mathrm{cm}^{3}$ \\
\hline Material pulverulento (\%) & $\begin{array}{c}\text { ABNT NBR NM } \\
46: 2003 \\
\end{array}$ & $1,0 \%$ & $1,3 \%$ & $0,29 \%$ & $0,9 \%$ \\
\hline
\end{tabular}

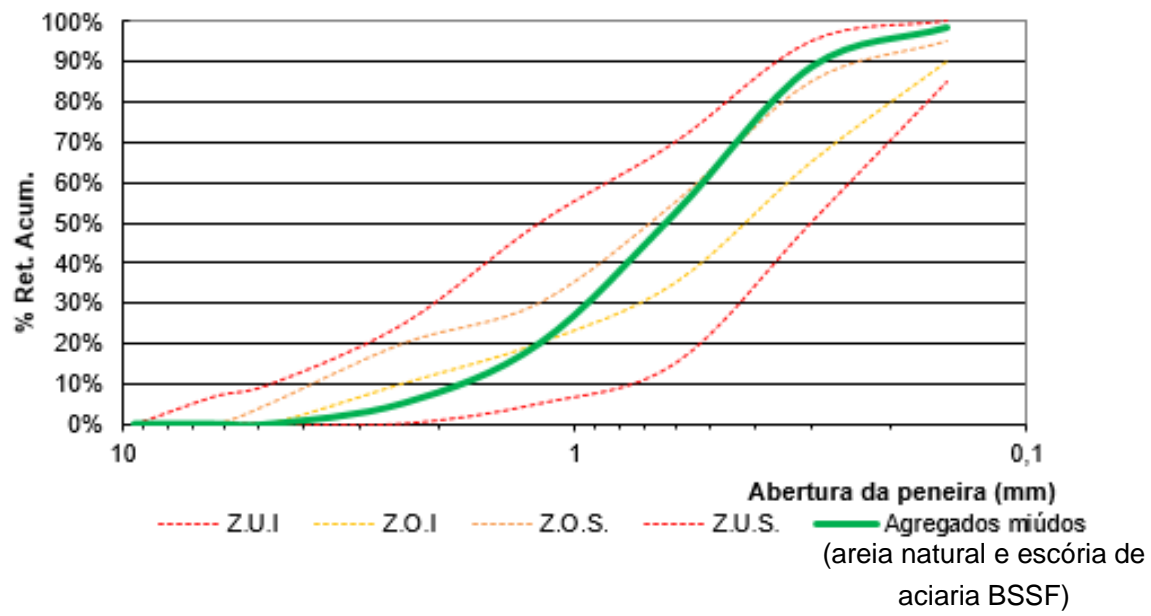

Figura 2: Distribuição granulométrica dos agregados miúdos utilizados na pesquisa, com especificação dos limites das zonas utilizáveis inferior (ZUI) e superior (ZUS) e zonas ótimas inferior (ZOI) e superior (ZOS).

A caracterização química da escória de aciaria BSSF pode ser observada na Tabela 2, onde encontram-se as concentrações dos principais óxidos, obtidas através do ensaio de Fluorescência de Raios-X (FRX), realizado no Laboratório de Raios-X do Departamento de Física da Universidade Federal do Ceará - UFC, utilizando o espectômetro Rigaku Simultix 14. A escória de aciaria BSSF é composta majoritariamente pelos óxidos $\mathrm{Fe} 2 \mathrm{O} 3$ e CaO.

Tabela 2 - Composição química da escória de aciaria BSSF.

\begin{tabular}{c|c|c|c|c|c|c|c|c|c|c}
\hline Óxidos & $\mathrm{Al}_{2} \mathrm{O}_{3}$ & $\mathrm{SiO}_{2}$ & $\mathrm{P}_{2} \mathrm{O}_{5}$ & $\mathrm{~K}_{2} \mathrm{O}$ & $\mathrm{CaO}$ & $\mathrm{TiO}_{2}$ & $\mathrm{Cr}_{2} \mathrm{O}_{3}$ & $\mathrm{MnO}$ & $\mathrm{Fe}_{2} \mathrm{O}_{3}$ & $\mathrm{Co}_{2} \mathrm{O}_{3}$ \\
\hline Amostra (\%) & 0,63 & 5,84 & 1,01 & 0,04 & 33,46 & 0,63 & 0,21 & 5,09 & 52,98 & 0,12 \\
\hline
\end{tabular}

Em relação ao fenômeno de expansibilidade, a escória de aciaria BSSF não apresentou expansão a frio e em relação à expansão a quente, todos os resultados obtidos encontraram-se dentro do limite máximo especificado de $5 \mathrm{~mm}$ pela NBR 16697 (ABNT, 2018). O ensaio foi realizado com base no ensaio de determinação da expansibilidade do cimento pelo método de Le Chatelier (ABNT NBR 11582:2016), sendo adotado um teor de substituição de cimento por escória de aciaria BSSF de 50\%, em volume. Para Mehta e Monteiro (2014), esse teor é suficiente para que o fenômeno ocorra, caso o material possua características expansivas.

Concernente à sua forma e textura, em ensaio realizado por meio do Aggregate Image Measurement System (AIMS), realizado no Laboratório de Mecânica dos Pavimentos - LMP da Universidade Federal do Ceará - UFC, observou-se que a escória de aciaria BSSF possui uma predominância de partículas alongadas e angulares, com textura rugosa. 


\subsection{Método de pesquisa}

Visando analisar a influência da substituição do agregado miúdo natural por escória de aciaria BSSF no concreto foram estudados os teores de substituição de $0 \%, 25 \%, 50 \%, 75 \%$ e $100 \%$, em volume, na produção de concretos com resistência característica (fck) de $40 \mathrm{MPa}$, totalizando cinco traços. Os traços adotados foram proveniente de central dosadora da cidade de Fortaleza Ceará, por serem os mais comercializados na região. A Tabela 3 apresenta o consumo de materiais por metro cúbico desses traços.

Tabela 3 - Consumo de materiais $\left(\mathrm{em} \mathrm{kg} / \mathrm{m}^{3}\right)$, para cada traço investigado.

\begin{tabular}{c|cccccccc}
\hline Traço & $\begin{array}{c}\text { Teor de } \\
\text { substituição }\end{array}$ & Cimento & $\begin{array}{c}\text { Areia } \\
\text { natural }\end{array}$ & $\begin{array}{c}\text { Escória } \\
\text { BSSF }\end{array}$ & $\begin{array}{c}\text { Brita } \\
\mathbf{1 2 , 5 m m}\end{array}$ & $\begin{array}{c}\text { Brita } \\
\mathbf{1 9 m m}\end{array}$ & $\begin{array}{c}\text { Aditivo } \\
(\mathbf{\%})\end{array}$ & a/c \\
\hline T40 & $0 \%$ & 440 & 710 & - & 266 & 709 & 0,33 & 0,41 \\
$\mathbf{T 4 2 5}$ & $25 \%$ & 440 & 532,5 & 248,1 & 266 & 709 & 0,38 & 0,41 \\
$\mathbf{T 4 5 0}$ & $50 \%$ & 440 & 355 & 496,2 & 266 & 709 & 0,41 & 0,41 \\
$\mathbf{T 4 7 5}$ & $75 \%$ & 440 & 177,5 & 744,3 & 266 & 709 & 0,43 & 0,41 \\
T4100 & $100 \%$ & 440 & - & 992,4 & 266 & 709 & 0,43 & 0,41 \\
\hline
\end{tabular}

Foram avaliadas as seguintes propriedades no estado endurecido: resistência à compressão, absorção de água por capilaridade, índices de vazios e resistência à penetrabilidade de íons cloretos. A avaliação da resistência à compressão dos concretos se deu a partir do ensaio realizado conforme preconiza a NBR 5739 (ABNT, 2018), nas idades de 3, 7 e 28 dias. Para avaliar o desempenho dos concretos produzidos quanto à permeabilidade e porosidade foram realizados os ensaios de absorção de água por capilaridade (ABNT NBR 9779:2012) e determinação do índice de vazios (ABNT NBR 9778:2009). Os corpos de prova submetidos ao ensaio de absorção de água por capilaridade foram previamente impermeabilizados com uma manta acrílica líquida, de modo a garantir que apenas a altura do corpo de prova especificada pela norma permanecesse em contato com a água.

A capacidade dos concretos produzidos em inibir a penetração de cloretos foi avaliada por meio do ensaio de penetrabilidade de íons cloretos, avaliando-se a carga total passante, conduzido de acordo com a norma ASTM C1202:2012 - Standard Test Method for Electrical Indication of Concrete's Ability to Resist Chloride Ion Penetration. O método consiste em acoplar uma fatia de concreto, com dimensões de 10 centímetros de diâmetro e 5 centímetros de altura, entre duas células acrílicas, sendo uma preenchida com solução aquosa com $3 \%$ de cloreto de sódio $(\mathrm{NaCl})$ e a outra com solução aquosa $0,3 \mathrm{~N}$ de hidróxidode sódio $(\mathrm{NaOH})$. A avaliação da penetração de íons cloretos é feita mediante a medição da carga passante (em Coulombs) na amostra de concreto, submetida a uma tensão de $60 \pm 0,1$ volts durante um período de 6 horas. A Figura 3 apresenta uma representação esquemática desse ensaio.

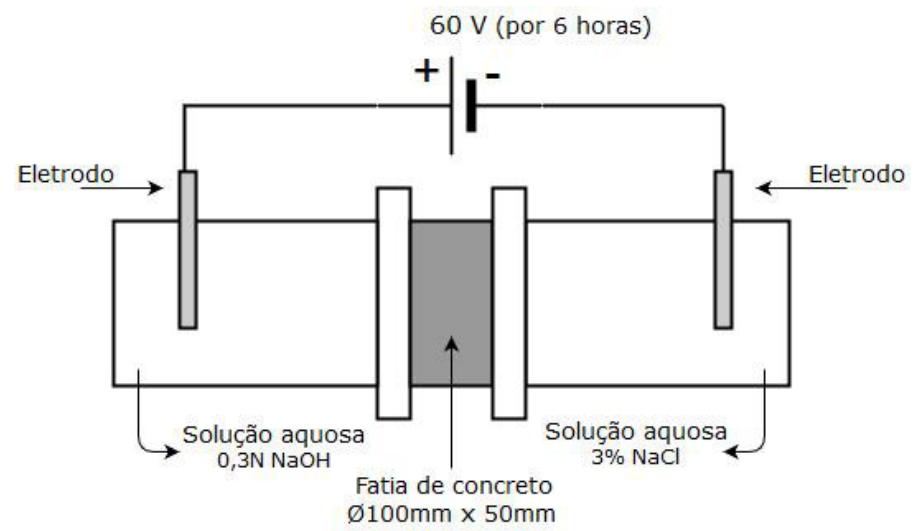

Figura 3: Representação esquemática do ensaio de penetrabilidade de íons cloretos. 
Para a realização do ensaio foram moldados dois corpos de prova cilíndricos de dimensões 10x20cm (diâmetro e altura) para cada traço e esperou-se a idade de cura de 28 dias para a execução do ensaio. Cada corpo de prova foi cortado em 5 fatias, sendo descartadas as fatias externas inferior e superior e coletadas as três fatias centrais como indicado na Figura 4, totalizando seis fatias para o traço. Seguindo a metodologia apresentada por Medeiros (2012), que afirma ser possível utilizar mais de uma fatia de um mesmo corpo de prova sem haver interferência nos resultados.

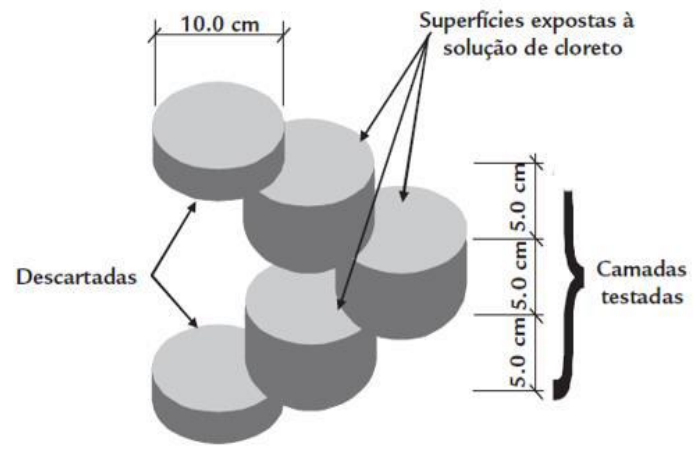

Figura 4: Esquema da extração de fatias do corpo de prova, para o ensaio de penetrabilidade de íons cloretos no concreto (Medeiros, 2012).

Posteriormente, foi realizada a seleção das fatias a serem utilizadas como amostras no ensaio, conforme proposto por Ribeiro (2010), de modo a garantir que as amostras ensaiadas fossem constituídas de porcentagem de fases próximas de agregado graúdo e matriz cimentícia. Para isso, foi utilizado o método de contagem de nós, sobrepondo uma grade de contagem sobre a amostra e somando os pontos da rede, sendo que nós que sobre puserem a zona de transição tem valor de 0,5 ponto e os que sobrepuserem o agregado graúdo tem valor de 1,0 ponto, conforme esquema observado na Figura 5. Em seguida, divide-se esse valordo somatório de pontos pela quantidade total de nós, estimando a porcentagem das fases, sendo selecionados as quatro amostras que mais se aproximem de um teor de argamassa médio.

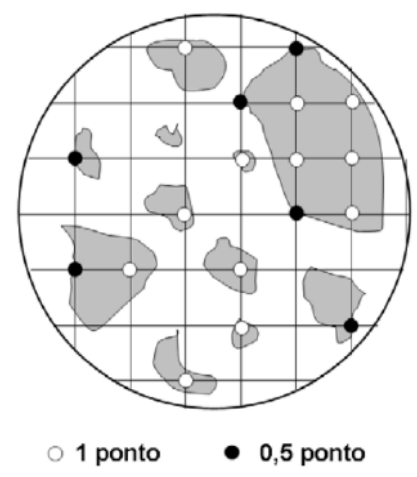

Figura 5: Esquema do procedimento de estimativa das fases do concreto, através da contagem de pontos em nós, proposto por Ribeiro (2010).

Após a seleção das amostras, estas foram acopladas no equipamento utilizado para a realização do ensaio (Figura 6). A leitura da corrente passante foi registrada com o auxílio de um amperímetro, em intervalos de trinta minutos. A carga passante foi calculada conforme os procedimentos da ASTM C 1202 (2012). A análise qualitativa seguiu a classificação de penetrabilidade de íons cloretos da ASTM C 1202 (2012), conforme exposto na Tabela 4.

Tabela 4 - Classificação proposta pela ASTM C 1202 (2012) para determinação do nível de penetrabilidade de íons cloreto no concreto.

\begin{tabular}{c|c}
\hline $\begin{array}{c}\text { Penetrabilidade de } \\
\text { íons cloreto }\end{array}$ & $\begin{array}{c}\text { Carga passante } \\
(\text { Coulombs }- \text { C) }\end{array}$ \\
\hline Alta & $\mathrm{C}>4000$ \\
\hline Moderada & $2000<\mathrm{C}<4000$ \\
\hline Baixa & $1000<\mathrm{C}<2000$ \\
\hline Muito baixa & $100<\mathrm{C}<1000$ \\
\hline Desprezível & $\mathrm{C}<100$ \\
\hline
\end{tabular}




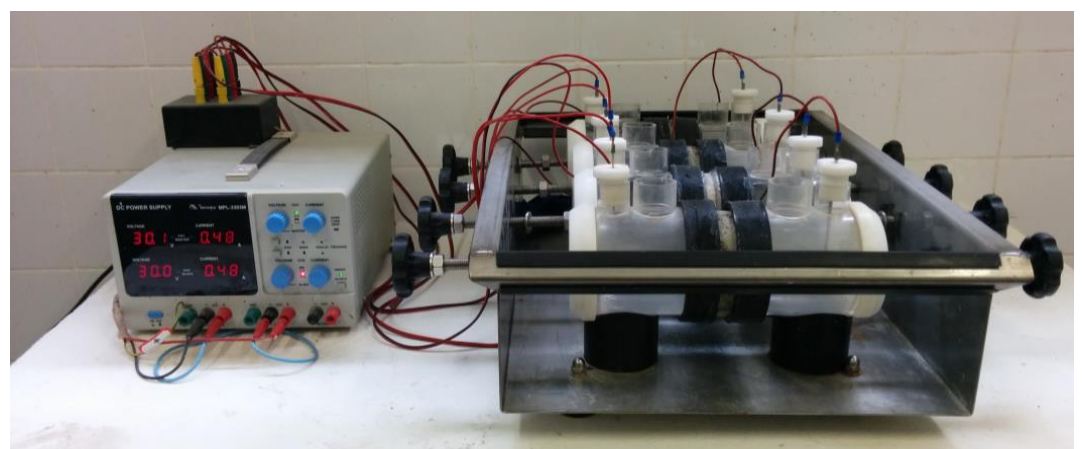

Figura 6: Aparelhagem para o ensaio de penetrabilidade de íons cloretos no concreto.

Para análise dos resultados, foram seguidas as etapas de identificação dos resíduos padronizados, eliminação dos dados espúrios, Análise de Variância (ANOVA) e Teste de Tukey, realizados com o auxílio do software Statistica 7.0. Foram considerados dados espúrios aqueles com valor excedente a um valor de referência de $\pm 1,96$ nos resíduos padronizados, a fim de que se tivesse um nível de confiança de 0,05 . Após a eliminação desses dados excedentes, foi realizada a Análise de Variância (ANOVA), um método paramétrico responsável por verificar se há diferença entre distribuição de uma medida entre grupos. Ao ser constatado pela ANOVA que há uma diferença significativa entre as médias dos grupos, foi aplicado um teste de comparações múltiplas, o Teste de Turkey. Esse teste verifica quais os grupos diferem dos demais, ao comparar cada par e reunir grupos com médias significativamente semelhantes. $\mathrm{O}$ resultado do Teste de Tukey foi representado graficamente através de grupos delimitados por retângulos que identificam quais médias não possuem diferença significativa entre si.

\section{RESULTADOS E DISCUSSÕES}

\subsection{Resistência à compressão}

A Tabela 5 apresenta os valores médios de resistência à compressão axial dos vários tipos de traços estudados, nas idades de ruptura de 3, 7 e 28 dias, com seus respectivos desvios-padrões.

Tabela 5 - Valores médios obtidos no ensaio de resistência à compressão para classe de resistência de $40 \mathrm{MPa}$ e teor de substituição analisados.

\begin{tabular}{c|c|c|c|c|c|c}
\hline \multirow{2}{*}{ Traço } & \multicolumn{6}{|c}{ Resistência à compressão $(\mathbf{M P a})$} \\
\cline { 2 - 7 } & \multicolumn{2}{|c|}{$\mathbf{0 3}$ dias } & \multicolumn{2}{c}{ 07 dias } & \multicolumn{2}{c}{ 28 dias } \\
\cline { 2 - 7 } & Média & $\begin{array}{c}\text { Desvio } \\
\text { Padrão }\end{array}$ & Média & $\begin{array}{c}\text { Desvio } \\
\text { Padrão }\end{array}$ & Média & $\begin{array}{c}\text { Desvio } \\
\text { Padrão }\end{array}$ \\
\hline T40 & 27,61 & 0,94 & 33,10 & 1,88 & 41,40 & 0,85 \\
\hline $\mathbf{T 4 2 5}$ & 34,63 & 2,95 & 41,08 & 1,69 & 45,32 & 0,80 \\
\hline $\mathbf{T 4 5 0}$ & 37,79 & 2,15 & 47,36 & 0,35 & 51,23 & 1,91 \\
\hline $\mathbf{T 4 7 5}$ & 40,76 & 0,97 & 44,36 & 0,72 & 50,82 & 2,05 \\
\hline $\mathbf{T 4 1 0 0}$ & 40,51 & 1,03 & 45,44 & 0,93 & 53,52 & 0,83 \\
\hline
\end{tabular}

Analisando os resultados obtidos para resistência à compressão, nota-se que nas idades de 3 e 7 dias, o traço de referência apresenta valores sigificativamente inferiores aos dos traços com presença de agregado alternativo. Com o avanço da idade do concreto de 3 dias para 7 dias, o traço de 50\% passa a diferir significativamente do traço de $25 \%$, se apresentando superior e não diferindo significativamente dos traços de $75 \%$ e $100 \%$. Já aos 28 dias, a mudança ocorre no traço de $25 \%$ que pasa a ser significativamente similar ao traço de referncia. Portanto, a utilização de teores de substituição de agregado natural por escória de aciaria BSSF a partir de 50\% ocasiona um aumento significativo (entre 23\% e 29\%) na resistência à compressão dos concretos da classe de 40 MPa quando comparado ao traço de referência . Os valores de acréscimo dessa propriedade foram próximos aos encontrados por Qasrawi et al. (2009), em pesquisa similar. 


\subsection{Absorção por capilaridade}

Os resultados médios obtidos no ensaio de absorção de água por capilaridade são apresentados na Tabela 6, bem como seus respectivos desvios-padrões.

Tabela 6 - Valores médios para a absorção por capilaridade por tempo de ensaio para cada traço estudado.

\begin{tabular}{|c|c|c|c|c|c|c|c|c|c|c|}
\hline \multirow{3}{*}{ Traço } & \multicolumn{10}{|c|}{ Absorção por capilaridade $\left(\mathrm{g} / \mathrm{cm}^{2}\right)$} \\
\hline & \multicolumn{2}{|c|}{3 horas } & \multicolumn{2}{|c|}{6 horas } & \multicolumn{2}{|c|}{24 horas } & \multicolumn{2}{|c|}{48 horas } & \multicolumn{2}{|c|}{72 horas } \\
\hline & Média & $\begin{array}{l}\text { Desvio } \\
\text { Padrão }\end{array}$ & Média & $\begin{array}{l}\text { Desvio } \\
\text { Padrão }\end{array}$ & Média & $\begin{array}{l}\text { Desvio } \\
\text { Padrão }\end{array}$ & Média & $\begin{array}{l}\text { Desvio } \\
\text { Padrão }\end{array}$ & Média & $\begin{array}{l}\text { Desvio } \\
\text { Padrão }\end{array}$ \\
\hline T40 & 0,025 & 0,000 & 0,038 & 0,000 & 0,064 & 0,000 & 0,076 & 0,000 & 0,121 & 0,009 \\
\hline T425 & 0,121 & 0,009 & 0,159 & 0,009 & 0,261 & 0,009 & 0,312 & 0,027 & 0,357 & 0,036 \\
\hline T450 & 0,376 & 0,027 & 0,376 & 0,027 & 0,395 & 0,036 & 0,401 & 0,045 & 0,401 & 0,045 \\
\hline T475 & 0,395 & 0,000 & 0,407 & 0,000 & 0,439 & 0,009 & 0,458 & 0,000 & 0,477 & 0,009 \\
\hline T4100 & 0,204 & 0,000 & 0,248 & 0,009 & 0,395 & 0,018 & 0,490 & 0,027 & 0,567 & 0,027 \\
\hline
\end{tabular}

Os resultados apresentados pelo ensaio de absorção de água por capilaridade no tempo de 72 horas (Figura 7) mostram que, de modo geral, traços produzidos com escória de aciaria BSSF apresentam valores significativamente superiores aos do traço de referência. A escória de aciaria BSSF tende a gerar concretos mais permeáveis, devido aos poros criados a partir do surgimento de vazios junto às paredes do agregado, por possuir forma mais angular que o agregado natural (LUXAN et al., 2000; QASRAWI, 2014).

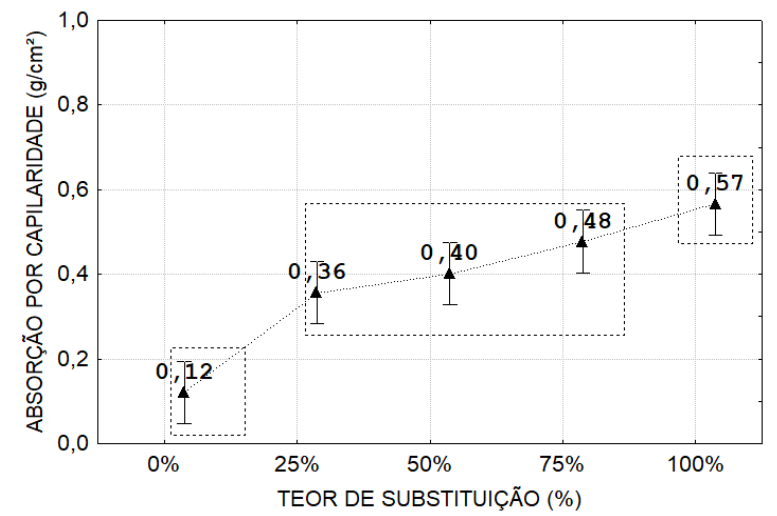

Figura 7: Análise da influência da escória de aciaria BSSF na absorção por capilaridade após 72 horas.

\section{3 Índices de vazios}

Os resultados médios obtidos no ensaio de índice de vazios são apresentados na Tabela 7, bem como seus respectivos desvios-padrões.

Tabela 7 - Valores médios obtidos no ensaio de índice de vazios para cada traço estudado

\begin{tabular}{c|c|c|c|c|c}
\hline \multirow{2}{*}{ Propriedade } & \multicolumn{5}{|c}{ Traço } \\
\cline { 2 - 6 } & $\mathbf{5 \%}$ & $\mathbf{2 5 \%}$ & $\mathbf{5 0 \%}$ & $\mathbf{7 5 \%}$ & $\mathbf{1 0 0 \%}$ \\
\hline $\begin{array}{c}\text { Índice de vazios } \\
(\%)\end{array}$ & 3,84 & 5,57 & 6,31 & 8,07 & 9,50 \\
\hline $\begin{array}{c}\text { Desvio padrão } \\
(\mathbf{M P a})\end{array}$ & 0,04 & 0,33 & 0,21 & 0,11 & 0,34 \\
\hline
\end{tabular}

Os resultados apresentados pelo ensaio de índice de vazios (Figura 8) mostram que, de maneira geral, traços produzidos com escória de aciaria BSSF apresentam valores significativamente superiores aos do traço de referência para a classe de resistência em análise. O aumento do teor de vazios nos traços com utilização de escória de aciaria BSSF pode ser atribuído à maior angularidade observada nas partículas desse agregado alternativo quando comparada com as da areia natural, devido à uma maior tendência a surgimento de vazios junto às paredes do agregado (QASRAWI, 2014; MEHTA; MONTEIRO, 2014). 


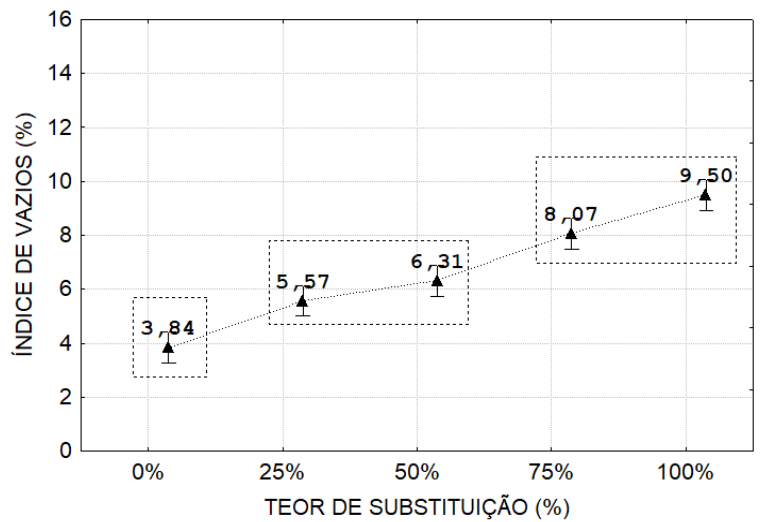

Figura 8: Análise da influência da escória de aciaria BSSF no índice de vazios.

\subsection{Penetração de íons cloretos}

$\mathrm{Na}$ Tabela 8 podem ser observados os valores médios e os desvios padrões dos resultados obtidos no ensaio de penetrabilidade de íons cloretos. Esses resultados representam a carga passante medida, em Coulombs.

Tabela 8 - Valores para a penetrabilidade de íons cloretos no concreto para cada classe de resistência e teor de substituição.

\begin{tabular}{c|c|c|c|c|c}
\hline \multirow{2}{*}{ Propriedade } & \multicolumn{5}{|c}{ Traço } \\
\cline { 2 - 6 } & $\mathbf{0 \%}$ & $\mathbf{2 5 \%}$ & $\mathbf{5 0 \%}$ & $\mathbf{7 5 \%}$ & $\mathbf{1 0 0 \%}$ \\
\hline $\begin{array}{c}\text { Penetrabilidade } \\
\text { de cloretos (C) }\end{array}$ & 1932 & 2488 & 3659 & 3659 & 3855 \\
\hline $\begin{array}{c}\text { Desvio padrão } \\
\text { (C) }\end{array}$ & 47 & 177 & 105 & 40 & 122 \\
\hline
\end{tabular}

Para a determinação da influência da escória de aciaria BSSF no grau de penetrabilidade de íons cloretos no concreto não foram realizados análises estatísticas, visto que sua análise é baseada exclusivamente na classificação da norma ASTM C 1202 (2012). Na Figura 9 estão apresentados os resultados obtidos para cada teor de substituição com a especificação do grau de penetrabilidade.

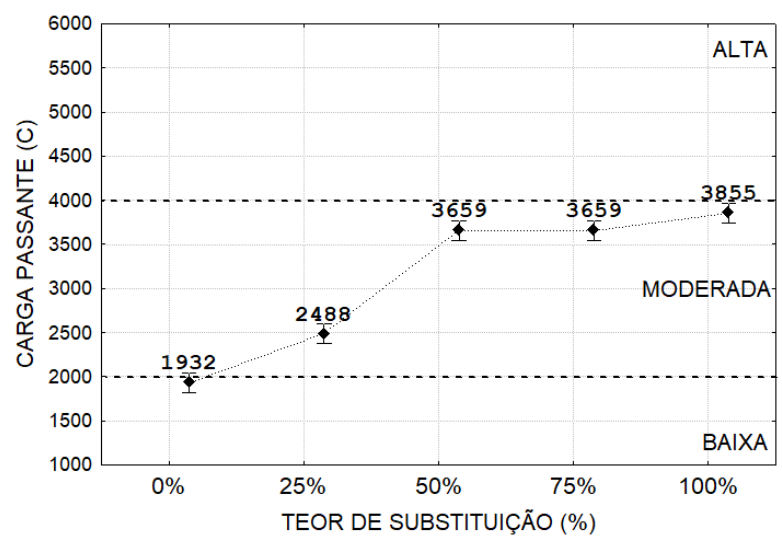

Figura 9: Análise da influência da escória de aciaria BSSF na penetrabilidade de íons cloretos. Os resultados apresentam a comparação entre teores de substituição para a classe de resistência 40 Mpa.

A partir dos resultados apresentados pelo ensaio de penetrabilidade de íons cloretos é possível observar um aumento dos valores para carga passante à medida que ocorre o aumento do teor de substituição de agregado miúdo natural por escória de aciaria BSSF no concreto. Este efeito é causado principalmente pelo aumento da porosidade e permeabilidade dos concretos produzidos com agregado alternativo. Para a classe de resistência em questão houve uma transição entres as classes de penetrabilidade. Houve a transição entre as classificações baixa e moderada, a partir do traço de teor de substituição de $25 \%$. 


\section{CONCLUSÃO}

Em relação aos resultados obtidos para a resistência à compressão, observou-se que a incorporação da escória de aciaria BSSF como substituto ao agregado natural fornece valores superiores para todas as idades da resistência analisada, apresentado um ganho máximo de $29 \%$ aos 28 dias de idade. Esses resultados podem ser justificados pelo aumento da ligação entre as partículas e a pasta de cimento, ocasionadas pela maior angularidade e textura rugosa da escória de aciaria BSSF em relação ao agregado miúdo natural, causando um maior intertravamento mecânico e fortalecendo a zona de transição do concreto.

Em contrapartida, o formato angular e textura rugosa da escória de aciaria BSSF contribuíram para o aumento da porosidade do concreto, trazendo como consequências, o aumento da absorção, aumento do índice de vazios e aumento da capacidade de penetração de íons cloretos. Os resultados apresentados pelo ensaio de absorção por capilaridade mostram que, de modo geral, traços produzidos com escória de aciaria BSSF apresentam valores significativamente superiores aos do traço de referência.

A partir dos resultados apresentados pelo ensaio de penetrabilidade de íons cloretos é possível observar um aumento dos valores para carga passante, indicando que o aumento do teor de escória de aciaria BSSF no concreto tende a aumentar o grau de penetrabilidade dos íons cloreto. Observou-se que para a classe de resistência analisada, houve uma transição entres as classes de penetrabilidade, a partir de $25 \%$. Entretanto, é válido ressaltar, que os traços alternativos dessa classe de resistência ainda se mantiveram como penetrabilidade moderada de íons cloretos.

\section{AGRADECIMENTOS}

Os autores agradecem ao Programa de Pós-Graduação em Engenharia Civil: Estruturas e Construção Civil (PEC) e ao Laboratório de Materiais de Construção Civil (LMCC), ambos da Universidade Federal do Ceará - UFC. O presente trabalho foi realizado com apoio da Coordenação de Aperfeiçoamento de Pessoal de Nível Superior - Brasil (CAPES) Código de Financiamento 001.

\section{REFERÊNCIAS}

ASSOCIAÇÃO BRASILEIRA DE NORMAS TÉCNICAS. NBR 12655: Concreto de cimento Portland - Preparo, controle e recebimento - Procedimento. Rio de Janeiro, 2006.

ASSOCIAÇÃO BRASILEIRA DE NORMAS TÉCNICAS. NBR 15900-1: Água para amassamento do concreto Requisitos. Rio de Janeiro, 2009.

ASSOCIAÇÃO BRASILEIRA DE NORMAS TÉCNICAS. NBR 16605: Cimento Portland e outros materiais em pó - Determinação da massa específica. Rio de Janeiro, 2017.

ASSOCIAÇÃO BRASILEIRA DE NORMAS TÉCNICAS. NBR 16697: Cimento Portland - Requisitos. Rio de Janeiro, 2018.

ASSOCIAÇÃO BRASILEIRA DE NORMAS TÉCNICAS. NBR 5739: Concreto - Ensaio de compressão de corpos de prova cilíndricos. Rio de Janeiro, 2018.

ASSOCIAÇÃO BRASILEIRA DE NORMAS TÉCNICAS. NBR 5752: Materiais pozolânicos - Determinação do índice de desempenho com cimento Portland aos 28 dias. Rio de Janeiro, 2014.

ASSOCIAÇÃO BRASILEIRA DE NORMAS TÉCNICAS. NBR 6118: Projeto de Estruturas de Concreto Procedimentos. Rio de Janeiro, 2014.

ASSOCIAÇÃO BRASILEIRA DE NORMAS TÉCNICAS. NBR 7211: Agregado para concreto - Especificação. Rio de Janeiro, 2009.

BASHEER, L.; KROOP, J.; CLELAND, D. J. Assessment of the durability of concrete from its permeation properties: a review. Construction and Building Materials, 2001. 
BRAND, A. S. ROESLER, J. R. Steel furnace slag aggregate expansion and hardened concrete properties. Cement \& Concrete Composites. Volume 60, 2015, p. 1-9.

CHEN, F. Application of detection for stability of concrete in concrete quality evaluations, Fujian Constr. Sci. Technol. v. 3, p. 47-48, 2011.

CHESNER, W. H. STEIN, C. W. COLLINS, R. J. VAN HELDEN, L. Waste and recycled materials in the transportation industry. NCHRP 4-21 - Information Database, version 1.0.8. American Association of State Highway and Transportation Officials, 2001.

GARCIA, R. B.; PADARATZ, I. J.; SZPOGANICZ, B. Agressividade marinha medida pela taxa de deposição de cloretos na Região da Grande Florianópolis. IN: $49^{\circ}$ CONGRESSO BRASILEIRO DO CONCRETO. Anais. Bento Gonçalves, IBRACON, 2007.

HUANG, K. J. DENG, M. SHEN, Y. Q. MO, L. W. Failure analysis of early age cracking of paving concrete in Donghai country, J. Wuhan Univers. Technol. v. 32, p. 62-66, 2010.

LIU, Y., WANG, X. Application of the BSSF molten steel slag processing technology in POSCO. Baosteel Technical Research; Shanghai. v. 5, ed. 2, p. 20-23, 2011.

MEDEIROS, M. H. F. GOBBI, A. GROENWOLD, J. A. HELENE, P. Previsão da vida útil de concreto armado de alta resistência com adição de metacaulim e sílica ativa em ambientes marinhos. Rem: Rev. Esc. Minas, Ouro Preto, v. 66, n. 1, mar. 2013.

MEDEIROS, M. H. F. BORBA, A. Y. HOPPE FILHO, J. HELENE, P. R. L. Ensaio de migração de cloretos para concreto: influência do número de fatias extraídas. REM: Revista Escola de Minas, Ouro Preto - SP, v. 65, n.4, p. 475-481, 2012.

MehtA, P. K.; MONTEIRO, PAUlo J. M. Concreto - Estrutura, Propriedades e Materiais. $3^{\text {a }}$. ed. São Paulo: Ibracon, 2014.

MO, L. ZHANG, F. DENG, M. JIN, F. AL-TABBAA, A. WANG, A. Accelerated carbonation and performance of concrete made with steel slag as binding materials and aggregates. Cement and Concrete Composites. Volume 83, 2017, p. 138-145.

QASRAWI, H. The use of steel slag aggregate to enhance the mechanical properties of recycled aggregate concrete and retain the environment. Construction and Building Materials. Volume 54, 2014, p. 298-304.

RIBEIRO, D. V. Influência da adição de lama vermelha nas propriedades e na corrosibilidade do concreto armado. Tese (Doutorado). Programa de Pós-Graduação em Ciência e Engenharia de Materiais. São Carlos, 2010.224 p.

SANTOS, D. V. Avaliação de teor de íons cloro no ar atmosférico da praia do porto das dunas, em Aquiraz/Ce. 2013. 78 f. Monografia - Centro de Tecnologia, Universidade Federal do Ceará, Fortaleza. 2013.

SILVA FILHO, L. C. P. Durabilidade do concreto à ação de sulfatos: análise do efeito da permeação de água e da adição de microssílica. Porto Alegre-RS, 1994. 143 p. Dissertação (Mestrado). Universidade Federal do Rio Grande do Sul.

SILVIA, C. N. HYPOLITO, R. RIBEIRO, A. A. Disponibilidade de metais pesados em aterro de indústria siderúrgica. Engenharia Sanitária e Ambiental. V. 11, n³, p. 196-202, 2006.

SOUZA, V. C.; RIPPER, T. Patologia, recuperação e reforço de estruturas de concreto. São Paulo: Pini, 1998.

SZEKELY, J. TRAPAGA, G. Industrial ecology-The need to rethink the materials cycle: Some problems, solutions, and opportunities in the materials field. Journal of Materials Research. V. 10, p. 2178-2196, 1995. 